\title{
A CONSAGRAÇÃO DA FAMÍLIA CONTEMPORÂNEA COMO ESPAÇO ESSENCIAL AO DESENVOLVIMENTO DA PESSOA HUMANA
}

\author{
Márcia Cristina dos Santos Rêgo ${ }^{1}$
}

\section{RESUMO}

Tem-se por objetivo central compreender a consagração da família contemporânea como espaço essencial ao desenvolvimento da pessoa humana. Trata-se de pesquisa bibliográfica qualitativa, com enfoque indutivo. Estrutura-se em dois tópicos principais. A um, faz-se uma analise de documentos históricos relevantes à compreensão do panorama jurídico da família contemporânea, em especial no contexto do constitucionalismo social e da consolidação progressiva dos direitos humanos. A dois, a compreensão da centralidade da pessoa humana na ordem vigente permite compreender que a essencialidade da família ao desenvolvimento da pessoa humana reside na sua instrumentalidade da proteção e da humanização de indivíduos e da sociedade.

Palavras-chave: Família contemporânea. Direitos humanos. Desenvolvimento da dessoa humana.

\section{THE CONSECRATION OF CONTEMPORARY FAMILY AS AN ESSENTIAL SPACE FOR THE DEVELOPMENT OF HUMAN PERSON}

\begin{abstract}
To understand consecration of contemporary family as an essential space for human person development, this qualitative bibliographic research, with inductive focus, is structured into two main topics. At one, an analysis of historical documents relevant to understanding the legal landscape of contemporary family is made, especially in the context of social constitutionalism and the progressive consolidation of human rights. At two, understanding the centrality of the human person in current order allows us to understand that the essentiality of the family to the development of human person lives in its instrumentality of protection and humanization of individuals and society.
\end{abstract}

Key-words: Contemporary Family. Human rights. Human person development .

\section{INTRODUÇÃO}

A necessidade de compreender a relevância da família contemporânea para o indivíduo e para a coletividade compele o estudioso do direito a investigar as nuances de sua regulamentação.

\footnotetext{
${ }^{1}$ Doutora em Direito pela UFPA em cotutela internacional com a Universidade de Lisboa. Professora de Direito Civil da Faculdade de Direito da UFPA. End postal: Tv Angustura, no 2932, ap 2201-B, Marco, 66093-040, Belém/PA. Email: marciacristinaufpa@hotmail.com.
} 
Os valores impregnados nessa regulamentação, seja por meio de regras ou princípios, conduzem ao entendimento de que a família contemporânea foi consagrada como espaço essencial ao desenvolvimento da pessoa humana, estabelecendo uma relação direta entre direito de família e direitos humanos, entre família e direitos fundamentais.

Porque a família é compreendida como espaço adequado e essencial para que esses direitos sejam ensinados, experimentados, praticados e tenham sua relevância reforçada para a vivência social de cada pessoa; habilitando cada indivíduo para assumir sua posição social como cidadão conhecedor dos direitos que lhe são inerentes, em face da coletividade, assim como das responsabilidades correspondentes.

Por essa razão, utilizando a pesquisa bibliográfica e o método indutivo, com o objetivo de compreender a consagração da família contemporânea como espaço essencial ao desenvolvimento da pessoa humana, estrutura-se o presente trabalho em um tópico denominado visão panorâmica da regulamentação constitucional da família contemporânea e outro denominado a família como espaço essencial ao desenvolvimento da pessoa humana.

No primeiro tópico faz-se um apanhado da forma como a família contemporânea é tratada nas mais variadas Constituições estrangeiras e em instrumentos históricos, impactando na sua consagração enquanto espaço essencial para o desenvolvimento da pessoa humana, em especial no contexto do constitucionalismo social revelado a partir de 1917 com a Constituição do México.

Dá-se especial enfoque à Constituição de Weimar de 1919, cuja influência sobre outros ordenamentos o justifica, e cuja relevância atribuída à família é notável. E destaca-se a sintonia entre os ordenamentos jurídicos das nações europeias após a Segunda Guerra Mundial e os instrumentos internacionais de proteção aos direitos da pessoa humana, revelando a relação entre os direitos humanos e o direito de família.

A tutela jurídica da família, nesse contexto, sinaliza a imprescindibilidade da tutela integral da existência humana em seus aspectos mais privados e íntimos para assegurar o desenvolvimento integral da pessoa e o progresso social. Então, ela recebe a incumbência de promover a realização dos direitos humanos.

No segundo tópico descortina-se efetivamente a família como espaço essencial ao desenvolvimento da pessoa humana. Partindo-se da compreensão da pessoa humana enquanto 
valor central do ordenamento jurídico internacional e nacional, e, portanto, da subjetivação do direito a partir desse fato. Conduzindo-se ao entendimento do papel da família no contexto dessa subjetivação, enquanto instrumento de proteção e de humanização de indivíduos e da sociedade.

\section{VISÃO PANORÂMICA DA REGULAMENTAÇÃO CONSTITUCIONAL DA FAMÍLIA CONTEMPORÂNEA}

A compreensão da visão da família contemporânea no direito estrangeiro e na perspectiva internacional requer referência a instrumentos legislativos históricos que produziram impacto na transição da era da família exclusivamente patriarcal e matrimonial para a atual era do pluralismo familiar, incompatível com a taxatividade legal dos formatos de família dignos de proteção.

Apesar do constitucionalismo social ter sido inaugurado pela Constituição Mexicana de 1917, que consagrou dimensões diferentes de direitos fundamentais, imputando ao Estado Democrático de Direito a obrigação de proteger seus cidadãos e toda a coletividade, além do respeito aos seus direitos, exigindo-lhe condutas positiva e negativa, conforme seja o interesse em questão, como o de promover a igualdade substancial ou de proteger a família, por exemplo.

Este trabalho toma o outro marco histórico desse constitucionalismo como instrumento inicial para referenciar o cuidado com a família, a Constituição de Weimar de 1919, considerando a projeção e influência exercida sobre os demais ordenamentos jurídicos a partir de então.

Ela trazia o casamento como o fundamento da família e tinha essa família formada a partir do casamento como fundamento da conservação e desenvolvimento da nação. Logo, proteger o casamento era proteger a família, e proteger a família era proteger a própria nação. Portanto, sem desconsiderar o apego ao modelo formal de família, destaca-se a relevância atribuída constitucionalmente à família naquele momento. 
O interessante é que a Constituição de Weimar consagrava a igualdade de direitos entre os sexos na sequência do enaltecimento ao casamento. $\mathrm{O}$ que revela-lhe uma interessante faceta; pois, por mais que se pudesse compreender que atribuía igualdade de direitos entre os cônjuges, isso não excluía a interpretação de que a igualdade de direitos entre os sexos transcendia a relação conjugal.

Outro aspecto a ser destacado é quanto à educação dos filhos, compreendida como um dever supremo e um direito natural dos pais com o objetivo de assegurar seu aperfeiçoamento físico, moral e social, sob a fiscalização da sociedade. Além disso, estabelecia que os filhos ilegítimos tinham direito às mesmas condições de desenvolvimento físico, moral e social que os filhos legítimos.

A Constituição Portuguesa de 1933, ainda que tenha sido influenciada pela Constituição de Weimar, não dedicou atenção à família naqueles termos. Apenas com a revisão constitucional de 1971, a família passou a ser referida como fonte de conservação e desenvolvimento do povo português, baseada exclusivamente no casamento e na filiação legítima.

A Constituição Irlandesa de 1937 também protegia o casamento, reconhecia a família como sendo a base necessária da ordem social, imprescindível ao bem-estar da nação, enquanto "grupo primário, natural e fundamental da sociedade" e "instituição moral investida de direitos inalienáveis e imprescritíveis, anteriores e superiores a qualquer disposição positiva" (MIRANDA, 2014, p. 78)

As Constituições Européias que sucederam à Segunda Guerra Mundial foram todas no sentido de proteger a família e reconhecerem sua relevância social (Constituições Francesas de 1946 e 1958, Constituição Italiana de 1947, Constituição Alemã de 1949, Constituição Grega de 1975, Constituição Portuguesa de 1976, Constituição Espanhola de 1978) em sintonia com os instrumentos internacionais de proteção aos seres humanos, como a Carta das Nações Unidas de 1945 e a Declaração Universal dos Direitos Humanos de 1948, num entrelaçamento simbiótico entre os ordenamentos internos de cada nação e o ordenamento internacional voltado à proteção da pessoa humana.

Pois, neste ponto é relevante destacar que, a preocupação em proteger a família deixa de ser primordialmente em face de ela ser considerada a instituição jurídica base do Estado e 
passa a ser em função da necessidade da proteção e da promoção da dignidade da pessoa humana. Assumindo a família uma posição instrumental estratégica para o desenvolvimento e realização de cada ser humano que vai integrar a comunidade global e a grande família humana.

A família assume, portanto, o ônus de criar, proteger, preparar e assegurar o desenvolvimento pleno da pessoa que ingressa na sociedade consciente de seus direitos e responsabilidades em busca da conquista da felicidade e de todos os objetivos constantes de seu projeto de vida. Ela funcionaliza a realização dos próprios direitos humanos.

Nesse sentido, o Pacto Internacional de Direitos Econômicos, Sociais e Culturais, de 1966, entende a família como sendo o núcleo natural e fundamental da sociedade, conclamando sua proteção e assistência na promoção dos direitos de seus integrantes, em especial na proteção de crianças e adolescentes.

Bem como, também em 1966, o Pacto Internacional dos Direitos Civis e Políticos reafirmou o dever do Estado de proteger a família e reconheceu o direito de homens e mulheres casarem e fundarem família. Fato que por si só deixa claro que o direito a casar e o direito a formar família são dois direitos distintos pertencentes a homens e mulheres. De forma que é possível formar família sem que haja casamento.

Em complemento, a Convenção sobre a eliminação de todas as formas de discriminação da Mulher, de 1976, fixou parâmetros a serem observados para que a mulher não sofra discriminação no seio da própria família, protegendo-a enquanto pessoa, em reconhecimento à vulnerabilidade decorrente do sistema patriarcal, que assegura posição de poder ao homem.

Essa Convenção influenciou diretamente, por exemplo, na Carta Africana dos Direitos Humanos e dos Povos, de 1981, onde é possível identificar a reprodução de alguns de seus dispositivos.

Reconhecendo a vulnerabilidade de crianças e adolescentes, tal qual a vulnerabilidade da mulher pela convenção anterior, a Convenção Internacional sobre os Direitos da Criança, de 1989, veio reforçar o direito da criança e do adolescente a ter uma família e a ser protegida pela família, pela sociedade e pelo Estado, também enaltecendo particularmente sua condição de pessoa em desenvolvimento. 
Fato que reforça a compreensão instrumental e fundamental da família para o desenvolvimento pleno do ser humano. Trata-se do lugar ideal e preferencial para que uma criança e um adolescente sejam criados; o que justifica a possibilidade de que na ausência da família natural, seja providenciada família substituta, que assuma aquele ônus, viabilizando a experiência da convivência familiar, essencial à formação do cidadão.

Nesse diapasão, a Comunidade para o Desenvolvimento dos Povos da África Austral (SADC) adotou o Protocolo sobre Gênero e Desenvolvimento em 2008, estabelecendo normas sobre casamento e direito de família, direitos de viuvez e crianças, com o propósito de combater questões sociais contemporâneas atentatórias aos direitos humanos nos países daquela região (MEDINA, 2011, p. 39).

O processo de globalização, aparentemente irreversível, aliado aos grandes êxodos testemunhados na atualidade, impulsionando a formação de famílias por indivíduos de nacionalidades e culturas completamente diversas, num território que pode ser alheio a qualquer de suas nacionalidades, por exemplo, sinalizam para a necessidade de que sejam criadas regras aptas a absorver e proteger essa nova realidade. Natural, portanto, que países, como os africanos, consorciem seus esforços para a "criação de normas comuns de direito de família” com a finalidade de evitar conflitos. (MEDINA, 2011, p. 41)

Nesse sentido, a Conferência de Haia de Direito Internacional Privado tem realizado um esforço diplomático no sentido da promoção da harmonização das regras de direito de família entre os países que a integram. Brasil e Portugal estão entre seus Estados membros, que ratificaram, por exemplo, a Convenção Relativa à Proteção das Crianças e à Cooperação em Matéria de Adoção Internacional, em vigor a partir de $1^{\circ}$ de maio de 1995, com o objetivo de proteger crianças e suas respectivas famílias de adoções ilegais, do rapto, do comércio e do tráfico de crianças.

O preâmbulo dessa Convenção afirma que os países ratificantes reconhecem que a criança deve crescer em ambiente familiar para assegurar o harmonioso desenvolvimento de sua personalidade; e que esse ambiente familiar precisa oferecer como qualificadoras: um clima de felicidade, amor e compreensão. 
Fortalecendo o entendimento de que o direito à família é um direito fundamental ao desenvolvimento da pessoa humana e de que a família é um espaço que deve propiciar vivências de afeto, de socialização, de cooperação, de felicidade.

Enaltecendo a relevância da família enquanto escola para a vida colaborativa em sociedade, na construção da felicidade de cada um a partir das relações afetivas, do desenvolvimento e da realização dos laços de amor, de carinho, de cuidado.

No âmbito da União Européia há notícias de esforços doutrinários abundantes no sentido de promover a convergência entre os ordenamentos jurídicos no trato do direito de família, o que já teria resultado na aproximação da disciplinas de temáticas como a tutela de famílias não matrimoniais e de famílias formadas a partir da união entre pessoas de mesmo sexo (PEREIRA, 2018, p. 130), mas isso não significa que a uniformização legislativa dos países integrantes do bloco efetivamente ocorra.

A título de exemplo, a Comissão de Direito da Família Europeu, criada em $1^{\circ}$ de setembro de 2001, elaborou 20 princípios a serem observados em matéria de Divórcio e Alimentos entre ex-cônjuges (2004), 39 princípios em matéria de Responsabilidades Parentais (2007) e 58 princípios em matéria de Relações Patrimoniais entre Cônjuges (2013), diante da impossibilidade da instituição de um Código Civil Europeu e da uniformização do direito de família, considerando as diferenças existentes entre os Estados membros da Comunidade Européia. (PINHEIRO, 2016, pp. 79-82)

Ainda que referidos princípios não obriguem os Estados membros, o intuito é influenciar suas legislações internas a produzirem regras semelhantes, até porque os princípios em questão foram construídos a partir da regulamentação existente na maioria desses países (PINHEIRO, 2015, p. 390). Exemplo dessa influência em Portugal é a Lei no 61/2008, que altera o regime de divórcio, acolhendo princípios como o da admissibilidade do divórcio, das modalidades de divórcio e da determinação das consequências do divórcio, entre outros.

Entretanto, aparentemente, os aspectos que distinguem o direito de família dos países ocidentais estão sendo reduzidos e comprometendo sua singularidade cultural, fato que pode ser notado em Portugal já com a Reforma de 1977 (PINHEIRO, 2015, P. 169). Esse movimento de convergência, porque não parece adequado nominar de uniformização, 
decorreria do fato do legislador buscar inspiração no ordenamento jurídico do país vizinho para a tutela de questões na órbita familiar e do fato de que países signatários de Convenções Internacionais acabam por internalizar seus preceitos e regular de modo semelhante aspectos de questões familiares presentes em todas as sociedades. (PINHEIRO, 2015, p. 170)

Nessa perspectiva: "o direito de família dos países ocidentais não conhece fronteiras: regula internamente situações transnacionais mediante normas de outros ordenamentos, importa soluções e sujeita-se a fontes extraestatais.” (PINHEIRO, 2015, P. 389) Isso originou um núcleo ocidental comum de direito de família, materializado em princípios como o da igualdade entre cônjuges e não discriminação entre os filhos, por exemplo.

Ainda que muitas sejam as diferenças existentes na tutela da família, a tendência à convergência entre os ordenamentos jurídicos dos países ocidentais talvez seja explicada pelo não questionamento aos direitos fundamentais (PEREIRA, 2018, P. 129), considerando a imperatividade de sua observância para a adequada proteção da pessoa humana no âmbito familiar.

Desse modo, são efetivamente a Convenção Européia dos Direitos Humanos, as normas do Conselho da Europa, como os Regulamentos que incidem sobre as famílias, enquanto instrumentos de direito internacional privado da família, e as decisões do Tribunal Europeu de Direitos Humanos e do Tribunal de Justiça da União Européia, que interpretam essas normas supranacionais, que impulsionam a convergência dessas legislações naquele continente. (PEREIRA, 2018, p. 131)

Destaquem-se, ainda na Europa, a Constituição Polonesa de 1997 que enfatiza a responsabilidade do Estado com o bem da família, em especial aquelas que se encontrem em situação de vulnerabilidade social e financeira, onde nomeia as famílias numerosas, as famílias formadas por mães ou pais solteiros e seus filhos (colocando-os em pé de igualdade); e a Constituição Suíça de 1999, que enxerga as famílias como comunidades de adultos e crianças.

Na América do Sul, além da referência que a Constituição Brasileira de 1988 torna-se com a gama de proteção que confere à família, chama atenção o fato de que a Constituição Venezuelana de 1999 tem a família como uma associação natural da sociedade e como espaço fundamental para o desenvolvimento integral das pessoas, apesar de encontrar-se sob regime 
crescentemente autoritário e repressivo, desde 1992, o que tem culminado em agravada crise humanitária.

No âmbito do Mercosul, porém, não há documento que disponha sobre a família, no sentido de unificar ou promover a convergência de sua regulamentação.

No entendimento de Ruy Rosado de Aguiar Jr, a unificação dos vários direitos de família, ainda que em torno de um conceito inclusivo de família, representa um enorme desafio, pois decorreria de uma unidade de pensamento social e político, que uma breve analise dos vários sistemas jurídicos demonstra longe de existir, seja no Mercosul, seja na União Européia, apesar das Convenções que oferecem regras comuns aos países membros (AGUIAR JR, 1999, p.9), como regras atinentes à competência judiciária e à execução de decisões sobre questões de família e sucessões (AGUIAR JR, 1999, p.11) e regras atinentes a reagrupamento familiar a fim de permitir que os familiares do estrangeiro com ele vivam no país em que ele se estabelecer.

Para fim desse reagrupamento, a comunidade européia adota um conceito de família mais dilatado que a família nuclear, envolvendo: ascendentes e descendentes que vivam sob dependência do trabalhador estrangeiro, restringindo a conjugalidade ao casamento, sem contemplar a união estável ou a união de facto. (AGUIAR JR, 1999, p.15)

No Brasil, para fins de reunião familiar, em 1997, o Ministério das Relações Exteriores estava autorizado a conceder visto temporário ou permanente aos descendentes, compreendidos também os de $2^{\circ}$ e $3^{\circ}$ graus de parentesco, além dos colaterais de $2^{\circ}$ grau, quando órfãos, solteiros, menores de 21 anos e maiores que não pudessem prover seu próprio sustento, dependendo do estrangeiro aqui radicado, além do cônjuge e do ascendente que necessitasse de amparo, conforme entendimento do Conselho de Política da Imigração, na Resolução Normativa nº4/97 (DOU, I, 27/07/1997).

Atualmente, a vigente Portaria Interministerial $n^{\circ}$ 12, de 13 de junho de 2018, emitida pelos Ministros de Estado da Justiça, Extraordinário da Segurança Pública e das Relações Exteriores, em conformidade com o Decreto $\mathrm{n}^{\circ}$ 9.199, de 20 de novembro de 2017, traz a previsão de concessão de visto temporário para fins de reunião familiar, com validade de 1 (um) ano, e de concessão de autorização de residência, com validade de 2 (dois) anos, para imigrante: a) cônjuge ou companheiro, sem discriminação alguma, nos termos do 
ordenamento jurídico brasileiro; b) filho de brasileiro ou de imigrante beneficiário de autorização de residência; c) enteado de brasileiro ou de imigrante beneficiário de autorização de residência, desde que menor de dezoito anos de idade, ou até os vinte e quatro anos de idade, se comprovadamente estudante, ou de qualquer idade, se comprovada a dependência econômica em relação ao chamante; d) que tenha filho brasileiro; e) que tenha filho imigrante beneficiário de autorização de residência; f) ascendente até o segundo grau de brasileiro ou de imigrante beneficiário de autorização de residência; g) descendente até o segundo grau de brasileiro ou de imigrante beneficiário de autorização de residência; h) irmão de brasileiro ou de imigrante beneficiário de autorização de residência, desde que menor de dezoito anos de idade, ou até os vinte e quatro anos de idade, se comprovadamente estudante, ou de qualquer idade, se comprovada a dependência econômica em relação ao chamante; ou i) que tenha brasileiro sob a sua tutela, curatela ou guarda.

Percebe-se que houve a dilatação considerável daquele rol de imigrantes considerados família para fins de reunião familiar pelo Estado brasileiro, em 11 anos, acompanhando a expansão da compreensão de quem é família e de sua relevância para os sujeitos relacionados.

As Constituições de Timor Leste de 2002 e de Angola de 2010, na Ásia e na África, respectivamente, também consideram que a família é fundamental à organização da sociedade e ao harmonioso desenvolvimento da pessoa. (MIRANDA, 2014, p. 80) Ambas vão ao encontro do art $16, \mathrm{n}^{\circ} 1$ da Declaração universal dos direitos humanos que estabelece que todos tem direito a constituir família.

Nesse contexto, observa-se que não apenas os modelos ou formatos de entidades familiares multiplicaram-se, mas que o próprio modelo tradicional foi profundamente impactado pelas transformações constantes desses instrumentos; sendo quase possível afirmar que ele é hoje o extremo oposto daquilo que já fora antes da nova ordem internacional, em especial com as conquistas de mulheres, crianças, adolescentes, jovens e idosos.

Ademais, a internalização de princípios consagrados em instrumentos internacionais de tutela dos direitos humanos e dos direitos de grupos vulneráveis específicos, como o princípio do superior interesse da criança, da obrigação de proteção de idosos, crianças e pessoas com deficiência, de respeito à integridade de cada indivíduo integrante da família e da necessidade de promover-lhes o pleno desenvolvimento em atenção à dignidade da pessoa humana, entre tantos outros como os princípios da liberdade, da igualdade e da não discriminação; acabou 
por subsidiar esse processo de diversificação de modelos de família. Pois, cada pessoa passou a sentir-se livre e protegida para realizar escolhas distanciadas do modelo exclusivo, imposto como padrão em um passado próximo, em busca de felicidade e plena realização.

Mas há quem enxergue isso como um problema, afirmando que ocorreu o afastamento do modelo tradicional de família e sua substituição pelo modelo individualista, que ignora a comunidade familiar. (CAMPOS, 2018, p. 14) Essa sobreposição do indivíduo sobre à família seria o problema, seria exatamente o que a prejudicaria enquanto comunidade, inclusive economicamente. Pois:

\begin{abstract}
a natureza da família reside na capacidade de amor de todos os seus membros, amor que determina uma comunidade de vida. A realidade da vida em conjunto é reconhecida como boa, amada, e sobre este amor forma-se uma comunidade de vida. Cada um é visto pelos outros, é reconhecido, num espaço de comunicação total, cada pessoa sendo vista e reconhecida em si mesma para além, muito além, da sua característica funcional, da sua utilidade (CAMPOS, 2018, p. 14)
\end{abstract}

Entretanto, é a habilidade de consorciar e harmonizar interesses e esforços para o desenvolvimento de cada integrante da entidade familiar, com o fim de assegurar a felicidade de cada um e do todo, que caracteriza a família contemporânea. Além da vontade de integrar a família, da necessidade de pertencimento, de integração, de completude, da necessidade de compartilhamento de afeto, o sentimento de solidariedade e de responsabilidade de uns para com os outros membros do grupo doméstico que compele os sujeitos a permanecerem na família.

É fundamental sentir-se cuidado, sentir-se protegido, sentir-se amado, perceber a reciprocidade da afeição, sentir-se seguro dentro de um espaço, que não é necessariamente físico, mas no interior da esfera da intimidade, dentro de uma relação. É essencial, à realização do ser humano, ter com quem possa contar em qualquer situação existencial positiva ou negativa. E o modelo de família constituído revela a identidade de seus membros, como expressão de sua própria existência.

A família é aquele grupo de pessoas para quem desejam-se contar os grandes e pequenos acontecimentos do cotidiano, partilhar informações de como foi o dia e manifestar interesse por saber como foi o dia de cada um dos demais, se referido projeto deu certo ou não, quais os planos de trabalho, de estudos, de férias; pedir colo quando nada sair como o planejado ou celebrar junto cada pequena conquista. 
Portanto, ainda que o suporte material que a família dispõe para garantir o mínimo à existência digna das pessoas de seus membros tenha relevância inegável, o suporte imaterial é, sem dúvidas, o aspecto onde efetivamente a família se revela enquanto tal. Enquanto lugar para onde pretende-se voltar ao final de uma jornada de intensas atividades de estudo, trabalho ou lazer para fazer e receber um afago, partilhar momentos de intimidade, fazer a refeição conversando sobre os acontecimentos daquele dia ou simplesmente assistir tv juntos ou sentar-se ao lado em silêncio; lugar onde a intimidade é compartilhada e cada indivíduo sente-se seguro para moldar e descobrir a própria identidade ao longo de seu desenvolvimento; mostrar-se como realmente é, sem os filtros, que a sociedade impõe que sejam usados nas demais relações sociais e jurídicas.

\section{A FAMÍlIA COMO ESPAÇO ESSENCIAL AO DESENVOLVIMENTO DA PESSOA HUMANA}

Por força do artigo VI da Declaração Universal dos Direitos Humanos, todo ser humano tem o direito a ser reconhecido como pessoa perante a lei, em todos os lugares; assegurados seus direitos e liberdades inclusive contra o Estado (artigo $1^{\circ}$ da Convenção Americana de Direitos Humanos), vedada qualquer discriminação. Ademais, o reconhecimento da personalidade jurídica da pessoa humana, por si só, também é um direito, consagrado no artigo $3^{\circ}$ daquela Convenção.

Ilustrada encontra-se, portanto, a centralidade do ser humano enquanto valor máximo do ordenamento jurídico internacional, consolidado após a II Guerra Mundial.

Essa centralidade da pessoa, enquanto valor supremo fundamental aplica-se a todas as relações econômicas, sociais e jurídicas de todas as sociedades do globo terrestre; que autoriza a reconhecer a despatrimonialização da ordem social e jurídica com sua sucessiva personalização.

Os valores consagrados no preâmbulo da vigente Carta Magna brasileira refletem exatamente essa subjetivação do ordenamento; quando declarada a instituição do Estado Democrático, enquanto essencial para a efetiva proteção dos direitos humanos, tendo o propósito de assegurar o exercício dos direitos sociais e individuais, a liberdade, a segurança, o bem-estar, o desenvolvimento, a igualdade e a justiça, enquanto valores supremos de uma 
sociedade fraterna, pluralista e sem preconceitos; fundada na harmonia social e comprometida com a solução pacífica dos conflitos, nos âmbitos interno e internacional. (RÊGO, 2021, p. 27)

\begin{abstract}
A dignidade da pessoa humana é apontada, logo no art. $1^{\circ}$, como sendo um fundamento do Estado Democrático. E todos os objetivos da República voltam-se à proteção e promoção da pessoa humana, seja através da construção de uma sociedade livre, justa e solidária; da erradicação da pobreza e marginalização e da redução das desigualdades sociais; seja da promoção do bem de todos, livre de preconceitos de qualquer natureza. (RÊGO, 2021, p. 27)
\end{abstract}

Isso significa que é para a pessoa humana que convergem todos os benefícios da tutela constitucional e infraconstitucional, considerando-se que por uma questão de coerência do ordenamento, essa proteção expande-se verticalmente e alcança horizontalmente todos os ramos do direito, considerando a unidade do sistema jurídico.

Assim é que a regulamentação da família contemporânea precisa refletir os valores constitucionais. Porque se ela integra aquele sistema de valores constitucionalmente consagrados, é incoerente que com eles não se harmonize.

Disso também resulta que não é mais possível que o intérprete do direito despreze a Constituição Federal, atendo-se exclusivamente ao código civil e à legislação infraconstitucional em vigor quando submetida demanda familiar. Ele precisa considerar que inclusive as relações familiares foram ressignificadas pelos valores constitucionalmente consagrados; uma vez que a liberdade que a pessoa tem de constituir família não está sujeita à limitação de forma ou modelos de famílias admitidos, por exemplo.

Nesse sentido, a Declaração Universal dos Direitos Humanos estabelece em seu artigo $\mathrm{XVI}, \mathrm{n}^{\circ} 1$, que as pessoas são livres para formar família em condições de igualdade e sem quaisquer discriminações. O que significa dizer que a liberdade reconhecida para que as pessoas constituam família não está atrelada a modelos específicos ou padrão de família, mas à realização do valor supremo da dignidade da pessoa humana.

Desse modo uma vasta gama de fatores reunidos dá o tom para assegurar a constituição e manutenção da família contemporânea. Vontade, interesses comuns, esforços consorciados (que caracterizam a vida em comum), harmonia, respeito e afeto, por exemplo, são fundamentais para que ocorra a durabilidade ou perdurabilidade das relações horizontais, ou seja, aquelas que formam-se pelo casamento ou por união estável - para citar os exemplos mais tradicionais de conjugalidade. 
As relações familiares verticais têm também a vontade daquele que torna-se pai ou mãe como ponto de partida, somada aos demais fatores, como: a vontade de afeto e a responsabilidade de criar e educar o filho gerado, assumido ou adotado formal ou socioafetivamente, assegurando-lhe pleno desenvolvimento.

Essa gama de fatores variados, não uniformes, para a constituição das famílias é resultado do exercício das liberdades reconhecidas em lei, diante da subjetivação do direito que precisou ceder ao pluralismo e à diversidade que esse exercício origina.

Portanto, as transformações ocorridas no âmbito da família são na realidade reflexo desse novo panorama jusfamiliar internacional decorrente da personalização ou subjetivação do direito, conquistado com a consagração dos direitos humanos. Mas, seja qual for a relação ou o modelo familiar, o importante é que a família consiga desenvolver a instrumentalidade cunhada pela nova ordem.

Nesse sentido, atente-se para o fato de que a liberdade de constituir família, que a Declaração reconhece, envolve o próprio planejamento familiar, conferindo às pessoas a decisão sobre a permanência, a duração ou a dissolução do casamento ou da família constituída sem formalidades; uma vez que, se a família formal pode ser extinta, não pode haver impedimentos para que a família informal o seja.

No momento em que a família constituída afastar-se da funcionalidade para a qual fora constituída, oferecendo perigo à integridade de seus membros, ao seu desenvolvimento e realização, à sua felicidade ou à sua vontade é perfeitamente possível extinguí-la ou substituíla. Na realidade é inclusive legítimo fazê-lo, como se depreende da leitura dos dispositivos alusivos à perda e suspensão do poder familiar no código civil e no Estatuto da Criança e do Adolescente, assim como da colocação de crianças, adolescentes e idosos em família substituta, exemplificativamente.

Desse modo, a pessoa dispõe da

liberdade de constituir, de manter e de destituir família matrimonial ou de outra
modalidade à escolha da pessoa humana; uma vez que não há qualquer delimitação
sobre a morfologia das famílias que as pessoas podem formar e que estarão sujeitas
à proteção (RÊGO, 2021, p. 29).

Fato justificado pelo enunciado no artigo XII daquela Declaração que assegura que a família e a vida privada da pessoa humana não podem ser objeto de qualquer interferência ou ataque, nem pelo Estado nem por particular, assim como sua honra e reputação, esferas existenciais de reserva personalíssima. 
É nesse sentido que a Constituição Federal tutela a família contemporânea por meio de uma cláusula geral inclusiva, prevalecendo-se de um conceito indeterminado de família, que assegura a permeabilidade da rede de proteção criada às transformações e à heterogenia sociais.

A família integra, assim, a seara íntima do indivíduo, que goza de prerrogativas próprias para deixá-la a salvo de toda sorte de interferências, seja de particulares ou do Estado. E enquanto base da sociedade, portanto seu fundamento, ela goza de especial proteção do Estado (art. 226, CF), comprovada pelos vários dispositivos constitucionais que a ela fazem menção, como o art. 183, que confere o domínio de bem imóvel urbano ao indivíduo que exerce a posse contínua, preenchendo os requisitos legais, dentre os quais a utilização do bem para sua moradia ou de sua família.

Moradia essa que juntamente com a intimidade e a vida privada, por força dos incisos $\mathrm{X}$ e XI, do art. $5^{\circ}$ da Constituição, tem garantida a inviolabilidade, em harmonia com os dispositivos da Declaração.

Tudo isso porque é a família a primeira responsável por assegurar e promover os direitos das pessoas humanas que a integram, desde a infância, passando pela adolescência, a juventude e a fase adulta, até o envelhecimento, como se depreende dos arts. $226, \S 8^{\circ}, 227$ e 230, do Texto Constitucional.

É a família, seja ela a família natural ou uma família substituta, o ambiente considerado propício para promover o livre e digno desenvolvimento integral da pessoa humana, que congrega os aspectos físico, mental, moral, espiritual e social, nos termos dos arts. $3^{\circ}$ e 19 , do Estatuto da Criança e do Adolescente.

Em complemento, o parágrafo único do referido art. $3^{\circ}$, do ECA, destaca que a pessoa em desenvolvimento não pode ser objeto de qualquer espécie de discriminação e faz expressa menção à vedação de que a situação familiar ou qualquer condição que diferencie as famílias seja utilizada como pretexto para a discriminar, interferindo no seu pleno desenvolvimento.

Legalmente, portanto, a família funciona como um forte que protege a dignidade da pessoa humana, ao mesmo tempo em que forja cidadãos, conferindo-lhes sustento, moradia, educação, cultura, respeito, liberdade, convivência familiar, profissionalização, etc, assegurando que ela entre para a vida em sociedade ciente de seus direitos e responsabilidades. 
Esse processo é tão complexo, delicado e relevante para o indivíduo e para a sociedade que justifica a proteção integral e a prioridade absoluta legalmente conferidas à pessoa em desenvolvimento. Ademais, as fases iniciais da existência humana, quais sejam: infância e adolescência, são aquelas em que o ser humano encontra-se mais vulnerável. Por isso o imperativo legal de que nenhuma criança ou adolescente seja objeto de negligência, discriminação, exploração, violência, crueldade e opressão por ação ou omissão atentatória aos seus direitos fundamentais, nos termos do art. $5^{\circ}$ do ECA.

Reunidos elementos suficientes para compreender as razões que levam a polícia a analisar e reanalisar tantas vezes as condutas da mãe, dos familiares e dos empregados da família da criança de 4 anos de idade (H.), assassinada após inúmeras sessões de torturas supostamente impetradas pelo padrasto com conhecimento e testemunho de algumas daquelas pessoas, segundo informações divulgadas pela imprensa.

Portanto, mesmo quem não pratica a violência ou crueldade contra a criança pode ser responsabilizado por ter sido negligente na proteção de sua integridade física. E isso porque o dever de proteger os direitos fundamentais da pessoa em desenvolvimento é da família, da sociedade e do Estado. Logo, todos os cidadãos são solidariamente responsáveis pelo bemestar de crianças e adolescentes, conforme art. 227, da Constituição. E conhecer dos fatos criminosos sem tomar providências para a proteção da pessoa em desenvolvimento, reconhecidamente vulnerável, é extremamente grave.

Nesse sentido, notável a relevância do art. 32 da Convenção Americana sobre Direitos Humanos (Pacto de São José da Costa Rica), celebrada em São José da Costa Rica, em 22 de novembro de 1969, e promulgada no Brasil pelo Decreto no 678, de 6 de novembro de 1992 , que compreendendo a família como elemento natural e fundamental da sociedade, determina que toda pessoa tem deveres para com a família, a comunidade e a humanidade; enfatizando a importância individual e social da família.

Os instrumentos normativos internos e internacionais referidos não passam de ilustração do estado da arte quando o assunto é a proteção da família enquanto instrumento necessário ao desenvolvimento da pessoa humana, valor máximo da ordem jurídica internacional.

Tutelar a família e a vida familiar é tutelar um aspecto essencial da existência humana, uma dimensão inalienável de sua personalidade. É eleger o espaço adequado para a materialização dos direitos humanos, como um laboratório de humanização de pessoas que 
lhe permite experienciar direitos e deveres, absorver essas práticas e as reproduzir em suas relações sociais dentro e fora da família.

Certamente por isso, a Declaração Universal dos Direitos Humanos no $n^{\circ} 3$, do artigo XVI, ao reconhecer a família como o núcleo natural e fundamental da sociedade com direito à proteção da sociedade e do Estado, praticamente elevou o direito fundamental da família à condição de um interesse difuso, pois o reconhece essencial à própria coletividade, para além da pessoa humana. De forma que a família não teria sua função social reduzida a promover o desenvolvimento integral da pessoa humana, mas a promover a humanização da própria sociedade visando o bem-estar de todos os membros da sociedade solidária.

Parece corroborar essa ideia a Declaração Rosacruz dos Deveres do Ser Humano (21/09/2007), ao afirmar que todo indivíduo tem o dever de considerar a humanidade inteira como sua família e de fazer do humanismo a base de seu comportamento, em seu artigo $10^{\circ}$, preconizando a fraternidade que deveria orientar as atitudes humanas nas relações interpessoais.

Afina-se, essa Declaração, com o princípio da solidariedade social que orienta a primazia dos interesses de todos, distribuindo entre todos a responsabilidade por cada um e o compromisso com o todo; tomando por base a dignidade da pessoa humana, que confere a cada ser humano a titularidade de direitos que fundamentam sua existência.

\section{CONCLUSÃO}

Os documentos analisados no presente trabalho não deixam dúvidas sobre a relevância jurídica conquistada pela família ao longo do último século. Assim como deixam evidentes os valores que justificam essa conquista.

A devoção da nova ordem mundial à pessoa humana, enquanto valor primordial central, à proteção e promoção de sua dignidade e de seu desenvolvimento integral desembocam na ampliação das dimensões existenciais protegidas.

Fato que alcança naturalmente a família, nutrida pela tutela da igualdade, da não discriminação, da solidariedade, da ampliação das liberdades, da intimidade, da privacidade, dos direitos fundamentais, que asseguram a realização da dignidade da pessoa humana. 
Essa subjetivação do direito na seara familiar eleva a família contemporânea da condição de instituição jurídica à condição de entidade existencial, fundamental para o indivíduo e para a sociedade. Impondo ao Estado o dever de protege-la sem violá-la, observando os limites impostos pela autonomia privada e pela intimidade para não comprometer os projetos de vida familiar arquitetados para a realização de seus membros.

Na condição constitucionalmente consagrada de supedâneo da sociedade, a família assume uma posição privilegiada, enquanto espaço adequado e essencial ao desenvolvimento da pessoa humana, gozando de prerrogativas legais que contribuíram para sua transformação, diante da pluralidade e diversidade que o novo ordenamento congrega. Ao mesmo tempo em que recebe prioritariamente os ônus e responsabilidades desse processo, considerando que a prioridade é garantir proteção e desenvolvimento às pessoas.

Nessa perspectiva, a família contemporânea mostra-se um reflexo das conquistas paulatinas dos direitos humanos, servindo de instrumento à sua realização, funcionando como laboratório que habilita a pessoa para a vivência em sociedade como cidadã.

\section{REFERÊNCIAS}

AGUIAR JÚNIOR, R. R. A unificação supranacional do direito de família. Informativo Jurídico da Biblioteca Ministro Oscar Saraiva, Brasília, DF, v. 11, n. 2, p. 169-189, jul./dez. 1999. Disponível em: https://bityli.com/Yakxx. Acesso em: 29 jul. 2019.

CAMPOS, D. L.; CAMPOS, Mônica, M. Lições de Direito da Família. 4. ed. Coimbra: Almedina, 2018.

MEDINA, M. C. Direito de Família. Lisboa: Escolar, 2011.

MIRANDA, J. Sobre a relevância constitucional da família. Revista da Faculdade de Direito da Universidade do Porto, Porto, v. 11, p. 77-93, 2014.

PEREIRA, M. S. Direito da Família. 2. ed. Lisboa: AFFDL, 2018.

PINHEIRO, J. D. Estudos de direito da família e das crianças. Lisboa: AAFDL, 2015.

PINHEIRO, J. D. O direito da família contemporâneo. Coimbra: Almedina, 2016.

RÊGO, Márcia Cristina dos Santos. Definição jurídica de família à luz dos direitos humanos. 2021, 234 f. Tese (Doutorado) - Universidade Federal do Pará, Programa de Pósgraduação em Direito e Universidade de Lisboa, Faculdade de Direito, Belém, 2020. 
ROCHA, C. L. A. Vida digna: direito, ética e ciência. In: ROCHA, C. L. A. (coord.). O direito à vida digna. Belo Horizonte: Fórum, 2004. 